\title{
Polyploidy in Relation to Sexual Dimorphism in Charophyta
}

\author{
S. K. Bhatnagar \\ Laboratory of Algal Cytogenetics and Mutation Research, \\ Department of Botany, Bareilly College, Bareilly, India
}

Accepted May 10, 1987

Polyploidy indicates the multiplication of basic set of chromosomes and may be natural or artificially induced. The polyploid races show greatest endurence to the unfavourable conditions and indicate advancement over other forms having low ploidy level. The occurrence of polyploid forms in any genus shows an evolutionary trend. Polyploidy can be used successfully in speciation. Wood and Imahori (1965), while bringing up their Monograph and Iconograph on 'A Revision of the Characeae', considered that the sexual dimorphism reflects minor genetic variations and the dioecious taxa always possess half the chromosome number of its monoecious counterparts. This interpretation of Wood and Imahori (1965) was not supported by Sarma and Khan (1967), Sarma and Ramjee (1971), Sawa (1965), Proctor and Hotchkiss (1968), Ramjee and Bhatnagar (1978) and Bhatnagar (1981) on cytological grounds. Present paper deals with the correlation between polyploidy and sexual dimorphism in Charophyta.

\section{Discussion}

As revealed by Table 1, monoecious taxa of Chara corallina, Nitella furcata and Nitella gracilis have the chromosome numbers more than double than their dioecious counterparts thus refute the generalization of Wood and Imahori (1965).

In the genus Tolypella, the dioecious forms ( $T$. nidifica var. porteri and $T$. nidifica var. glomerata) have the same chromosome number as their monoecious forms ( $T$. nidifica var. glomerata) have. It indicates that dioecism and monoecism are not governed simply by the chromosome numbers but they must have some genetic diversity which may be understood by studying their karyotypic organisations.

Sawa (1965) attempted 'karyotypic analysis method' for understanding the validity of dioecism and monoecism in the taxonomy of charophytes. He pointed out that the monoecious forms of Nitella flexilis $(\mathrm{n}=12)$ have originated through hybridization between the two dioecious taxa having $\mathrm{n}=6$ out of which one is $N$. opaca $(\mathrm{n}=6)$. He suggested that $N$. opaca (a dioecious form) may not be considered as a counterpart of $N$. flexilis (monoecious form) but an independent specific status should be given to it.

The author, while dealing with the cytology and cytotaxonomic studies in Charophytes of Rohilkhand division, investigated in Chara corallina, C. corallina var. wallichii, Nitella furcata, $N$. mirabilis, $N$. superba, Tolypella prolifera, $T$. glomerata var. nidifica and $T$. intricata. The chromosome numbers reported in monoecious and dioecious forms have been presented in Table 1. It was reported during present investigations that the monoecious and dioecious forms of Chara, Nitella and Tolypella do not have 2:1 ratio of chromosome numbers thus indicating that they are not the counterparts of each other and may be treated as valid taxonomic criteria. For instance, the monoecious forms of Chara corallina have chromosome numbers three times than their dioecious counterparts viz. $C$. corallina var. wallichii $(\mathrm{n}=14)$. The chromosome ratios between monoecious and dioecious forms were reported as $1: 1,2: 1$ and $3: 1$ in the present study. 
In the genus Tolypella, monoecious and dioecious forms have the similar chromosome numbers (Table 1) but in the monoecious forms of $T$. glomerata, $\mathrm{n}=11$ and 33 were reported from India (Ramjee and Bhatnagar 1978) and U. S. A. (Sawa 1974) respectively. It clearly exhibits that the dioecious and monoecious forms of Tolypella may have similar chromosome numbers whereas the monoecious forms or the dioecious forms may have "chromosome multiples' within themselves. In $T$. glomerata, Sawa (1974) reported the chromosome numbers three times than its dioecious counterpart.

Table 1. Polyploidy and sexual dimorphism in Charophyta

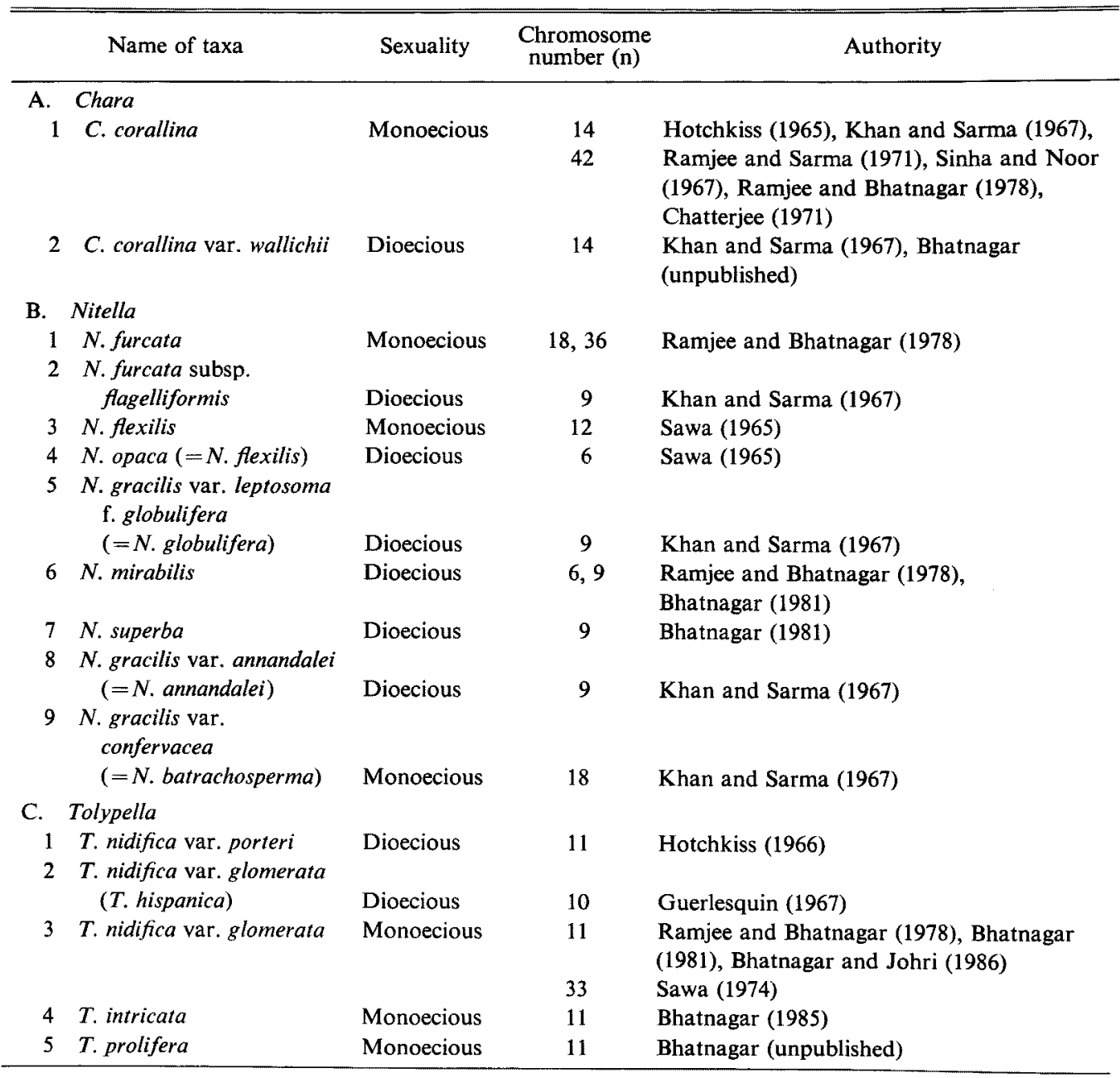

In view of Hotchkiss (1958), the dioecious forms have lesser chromosome numbers (not exactly half) than the monoecious one but it has not been supported because Tolypella glomerata (dioecious and monoecious both) and Chara corallina (dioecious and monoecious both) possess similar chromosome numbers irrespective of the sexual dimorphism. Ramjee (1969) however emphasized that polyploidy plays an important role in the diversification of dioecious taxa similar to the monoecious forms.

An overall conclusion of the present discussion highlights the taxonomic validity of dioecism and monoecism on cytotaxonomic grounds. 


\section{Summary}

Present paper deals with the cytological studies of monoecious and dioecious forms belonging to three Charophyte genera viz. Chara, Nitella and Tolypella. The taxonomic validity of sexual dimorphism has been discussed refuting the generalization of Wood and Imahori (1965).

\section{Acknowledgements}

The author is grateful to Dr. Ramjee, Department of Botany, Hindu College, Moradabad for his generous suggestions and to the University Grants Commission, New Delhi for financial assistance in the form of research project.

\section{References}

Bhatnagar, S. K. 1981. Cytotaxonomy of Charophytes of Rohilkhand division and effect of different chemicals on selected taxa. Ph. D. Thesis, Rohilkhand University, Bareilly.

- 1985. Tolypella intricata (Trent. ex Roth.) Leonh. em. R. D. W. from Indian subcontinent-A morphokaryological approach. Cryptogamie-Algologie (France) 4 (3): 185-190.

- and Johri, M. 1985. Mutagenic efficacies of triacontanol on Chara braunii (Div. Charophyta) with reference to its application in chromosome analysis. Crypto.-Algol. (France) 6 (4): 273-280.

Chatterjee, P. 1971. Cytological studies on Charophytes of West Bengal. Proc. 58th Indian Sci. Cong., Abstract No. 25.

Guerlesquin, M. 1967. Recherches caryotypiques et cytotaxonomiques chez les Charophycées. Thesis Dr. en Science, France.

Hotchkiss, A. T. 1958. Some chromosome numbers in Kentucky Characeae. Trans. Kentucky Acad. Sci. 19: $39-48$.

- 1965. Chromosome numbers in Characeae from South Pacific. Pacific Science 19: 31-37.

- 1966. A new and revised base chromosome number for the genus Tolypella. Bull. Torrey Bot. Club 93 (6): $426-432$.

Khan, M. and Sarma, Y. S. R. K. 1967. Some observations on the cytology of Indian Charophyta. Phykos $6(1 / 2): 62-74$.

Proctor, V. W. and Hotchkiss, A. T. 1968. Attempted hybridization between octa- and tetrascutate conjoined members of the genus Chara (Series Gymnobasalia). Manuscrit Dactylographie 17 p. (in ed. Ramjee 1969).

Ramjee 1969. Contributions to the systematics, cytology and cytotaxonomy of Indian Charophyta. Ph. D. Thesis, Banaras Hindu University.

- and Bhatnagar, S. K. 1978. Studies on Charophytes of Rohilkhand division 1. Moradabad. Taxonomic enumeration and chromosome counts. Phykos 17 (1/2): 87-93.

- and Sarma, Y.S. R. K. 1971. Some observations on the morphology and cytology of Indian Charophyta. Hydrobiologia 37 (2): 367-382.

Sarma, Y. S. R. K. and Khan, M. 1967. Dioecism and monoecism as taxonomic criteria in Charophyta. Curr. Sci. (India) 36: 245-246.

- and Ramjee 1971. Significance of chromosome numbers in Charophyta. A discussion. Caryologia (Italy) 24 (4): 391-401.

Sawa, T. 1965. Cytotaxonomy of the Characeae. Karyotype analysis of Nitella opaca and Nitella flexilis. Amer. J. Bot. 52 (9) : 962-970.

- 1974. New chromosome numbers for the genus Tolypella. Bull. Torrey Bot. Club 101 (1): 21-26.

Sinha, J. P. and Noor, M. N. 1967. Chromosome numbers in some members of Chlorphyceae of Chotanagpur Plateau, India. Phykos 6(1/2): 106-109.

Wood, R. D. and Imahori, K. 1965. A Revision of the Characeae. Monograph and Iconograph. Verlag von J. Cramer, Weinheim, West Germany. 